\title{
Kinetics and Spontaneous Open Probability Conferred by the $\epsilon$ Subunit of the $\mathrm{GABA}_{\mathrm{A}}$ Receptor
}

\author{
David A. Wagner, ${ }^{1}$ Marcel P. Goldschen-Ohm, ${ }^{2}$ Tim G. Hales, ${ }^{3}$ and Mathew V. Jones ${ }^{2}$ \\ ${ }^{1}$ Department of Biological Sciences, Marquette University, Milwaukee, Wisconsin 53201, 2Department of Physiology, University of Wisconsin, Madison, \\ Wisconsin 53706, and ${ }^{3}$ Departments of Pharmacology and Physiology, and Anesthesiology and Critical Care Medicine, The George Washington University, \\ Washington, DC 20037
}

$\mathrm{GABA}_{\mathrm{A}}$ receptors mediate synaptic and extrasynaptic inhibition. Native receptors consist of $\alpha$ and $\beta$ subunits, which are required for function, and another "modulatory" subunit, for example, $\gamma, \delta$, or $\epsilon$. Of these, the $\epsilon$ subunit has the most restricted distribution, confers resistance to neurosteroid and anesthetic modulation, and causes spontaneous channel opening. Little is known, however, about how $\epsilon$ affects receptor kinetics, which in turn shape responses to both ambient and synaptic GABA exposure. Here, we expressed human $\alpha 2 \beta 1$, $\alpha 2 \beta 1 \gamma 2$, or $\alpha 2 \beta 1 \epsilon$ subunit combinations in human embryonic kidney 293 cells and used rapid solution exchange to study receptor kinetics in outside-out patches. The $\epsilon$ subunit greatly slowed deactivation and recovery after brief GABA pulses. During long, saturating GABA pulses, the rate of desensitization was slower for $\alpha 2 \beta 1 \epsilon$ and $\alpha 2 \beta 1 \gamma 2$ than for $\alpha 2 \beta 1$. However, in $\alpha 2 \beta 1 \epsilon$, the final extent of desensitization was large compared with that of $\alpha 2 \beta 1 \gamma 2$. Responses in $\alpha 2 \beta 1 \epsilon$, but not the others, were often followed by an "overshoot" above the baseline, suggesting that a fraction of channels are spontaneously open and are transiently silenced by receptor activation and subsequent desensitization. The baseline current and associated noise were reduced by picrotoxin, revealing that $\epsilon$-containing channels are open $\sim 4 \%$ of the time in the absence of GABA. These results suggest that, if $\epsilon$-containing receptors are expressed at synapses, the synaptic currents would be long-lasting but may rundown quickly under high-frequency activation. In addition, silencing of spontaneous openings by desensitization raises the possibility that tonic inhibition mediated by $\epsilon$-containing receptors may be regulated by phasic inhibition.

Key words: kinetics; HEK293 cells; desensitization; deactivation; anesthetics; agonist-independent gating

\section{Introduction}

The neurotransmitter GABA exerts rapid inhibitory effects by binding to $\mathrm{GABA}_{\mathrm{A}}$ receptors. Enhancement of $\mathrm{GABA}_{\mathrm{A}}$ receptor activity by benzodiazepines and general anesthetics reduces anxiety, produces sedation, and inhibits epileptiform activity. In contrast, reduction of $\mathrm{GABA}_{\mathrm{A}}$ receptor function, either through pharmacological blockade or mutation, causes seizures (Baulac et al., 2001; Wallace et al., 2001; Harkin et al., 2002).

The receptor pentamer is formed by a combination of $\alpha, \beta, \gamma$, $\delta, \rho, \pi, \epsilon$, or $\theta$ subunits (Bonnert et al., 1999; Mehta and Ticku, 1999). Functional receptors can consist of $\alpha$ and $\beta$ subunits alone; however, native receptors usually include an additional "modulatory" subunit, typically $\gamma, \delta$, or $\epsilon$ (Whiting et al., 1999). $\mathrm{GABA}_{\mathrm{A}}$ receptor subunits are differentially compartmentalized among tissues and among cell types, as well as within single neurons (Luscher and Keller, 2004). For example, synaptic $\mathrm{GABA}_{\mathrm{A}}$ receptors often contain the $\gamma 2$ subunit, whereas extrasynaptic receptors often contain $\delta$ subunits (Nusser et al., 1998). The $\alpha \beta \delta$ combination has a higher affinity for GABA and slower desensi-

Received April 26, 2005; revised Sept. 28, 2005; accepted 0ct. 2, 2005.

This work was supported by National Institutes of Health Grant GM58037 (T.G.H.).

Correspondence should be addressed to David A. Wagner, Department of Biological Sciences, Marquette University, P.0. Box 1881, Milwaukee, WI 53201-1881. E-mail: david.wagner@marquette.edu. DOI:10.1523/JNEUROSCI.1658-05.2005

Copyright $\odot 2005$ Society for Neuroscience $\quad$ 0270-6474/05/2510462-07\$15.00/0 tization than most $\alpha \beta \gamma$ receptors, and mediates a tonic inhibitory current activated by low ambient GABA concentrations (Fisher and Macdonald, 1997; Haas and Macdonald, 1999; Farrant and Nusser, 2005). In addition, the $\alpha \beta \delta$ receptor is more sensitive to neurosteroid and anesthetic modulation than is the $\alpha \beta \gamma$ receptor (Wohlfarth et al., 2002; Stell et al., 2003; Feng and Macdonald, 2004; Feng et al., 2004).

It is also interesting to compare the $\epsilon$ and $\delta$ subunits. First, these subunits have somewhat complementary distributions. The $\epsilon$ subunit is concentrated in the hypothalamus and brainstem regions, such as the locus ceruleus and nucleus tractus solitarii (NTS), which tend to lack the $\delta$ subunit (Sinkkonen et al., 2000; Sergeeva et al., 2005). Second, the $\delta$ subunit increases the efficacy of neurosteroid modulation, whereas the $\epsilon$ subunit reduces neurosteroid and anesthetic modulation (Davies et al., 1997; Belelli et al., 2002; Thompson et al., 2002). Third, unlike any other known native $\mathrm{GABA}_{\mathrm{A}}$ receptors, those containing the $\epsilon$ subunit exhibit agonist-independent channel activity (Neelands et al., 1999; Davies et al., 2001; Maksay et al., 2003). However, such activity is expected to produce a tonic inhibitory current somewhat analogous to that mediated by $\delta$ subunit-containing receptors in other regions (Farrant and Nusser, 2005).

Because the $\epsilon$ subunit was discovered relatively recently, our understanding of its subcellular compartmentalization, pairing with other subunits, and role in regulating neural activity remains 
A

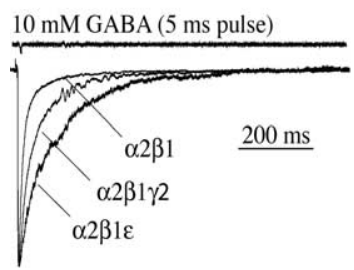

B

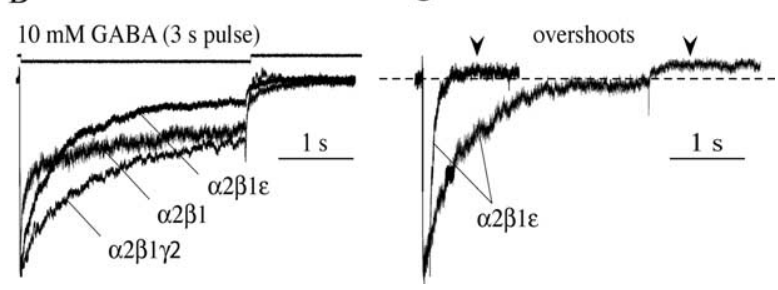

Figure 1. The $\epsilon$ subunit confers slow deactivation and desensitization. $A$, Outside-out patches from HEK293 cells transfected with $\alpha 2 \beta 1, \alpha 2 \beta 1 \gamma 2$, or $\alpha 2 \beta 1 \epsilon$ subunit combinations were repeatedly exposed to brief applications of saturating GABA. The averaged and normalized responses shown reveal that deactivation after the GABA pulse was significantly slower for $\alpha 2 \beta 1 \epsilon$ than for $\alpha 2 \beta 1$ and $\alpha 2 \beta 1 \gamma 2$ receptors. $\boldsymbol{B}$, Desensitization during long pulses of saturating GABA was also slower for $\alpha 2 \beta 1 \epsilon$ than for $\alpha 2 \beta 1$ but not for $\alpha 2 \beta 1 \gamma 2$ receptors. However, desensitization reaches a greater extent for $\alpha 2 \beta 1 \epsilon$ than for $\alpha 2 \beta 1 \gamma 2$ receptors. Parameters from biexponential fits and statistical results are given in Table 1. The top traces in $\boldsymbol{A}$ and $\boldsymbol{B}$ are liquid junction currents recorded at the open pipette tip to measure the speed of solution exchange ( $<200 \mu \mathrm{s}$ ). C, After removal of GABA from $\alpha 2 \beta 1 \epsilon$ receptors, a small outward overshoot current that crossed the resting baseline (dashed line) was observed in several experiments.

sketchy. It is not known whether the $\epsilon$ subunit participates in synaptic or extrasynaptic signaling, although the insensitivity of IPSPs in NTS neurons to benzodiazepines and of IPSCs in hypothalamic neurons to propofol may be attributable to $\epsilon$ subunitcontaining synaptic receptors (Kasparov et al., 2001; Sergeeva et al., 2005). Whether synaptic or extrasynaptic, the kinetic properties conferred by $\epsilon$ will determine its functional role. Few, if any, studies have examined responses of $\epsilon$ subunit-containing receptors to large and brief GABA transients, such as are likely at synapses, and none has quantified their probability of spontaneous opening. Here, we used rapid solution exchange methods to study the nonequilibrium kinetics of $\epsilon$-containing receptors.

\section{Materials and Methods}

Cell culture and transfection. Human embryonic kidney (HEK293) cells were cultured in minimum essential medium with Earle's salts (Invitrogen, Gaithersburg, MD) containing 10\% fetal bovine serum (SigmaAldrich, St. Louis, MO), penicillin (50-100 U/ml), and streptomycin $(50-100 \mu \mathrm{g} / \mathrm{ml})$ in a $37^{\circ} \mathrm{C}$ incubator under a $5 \% \mathrm{CO}_{2}$ atmosphere. When the cells reached $60-90 \%$ confluence, they were transfected using the calcium phosphate precipitation method, with $1 \mu \mathrm{g}$ total of human $\alpha 2$ and $\beta 1$ (weight ratio, $1: 1$ ), or $\alpha 2$ and $\beta 1$ plus $\gamma 2(1: 1: 1$ or $1: 1: 10)$ or $\epsilon$ (1:1:1) cDNAs per $35 \mathrm{~mm}$ dish, plus $100 \mathrm{ng}$ of enhanced green fluorescent protein cDNA to allow visualization of transfected cells. The $\alpha 2$ and $\beta 1 \mathrm{cDNAs}$ were contained in the same vector (pCIS2) and were a gift from Dr. Dolan Pritchett (formerly with University of Pennsylvania Medical School, Philadelphia, PA) (Jones et al., 1995). The $\gamma 2$ cDNA was subcloned into vector pcDNA3.1 (Bowser et al., 2002). The $\epsilon$ cDNA was subcloned into vector pCDM8 (Invitrogen) (Davies et al., 1997). Recordings were performed 24-96 h after transfection.

Patch-clamp electrophysiology. Recordings from outside-out patches excised from HEK293 cells were made using borosilicate glass pipettes filled with the following (in mM): $140 \mathrm{KCl}, 10$ EGTA, 2 MgATP, 20 phosphocreatine, and 10 HEPES, pH 7.3, 315 mOsm. Patches were voltage-clamped at $-60 \mathrm{mV}$ and placed in the stream of a multibarrelled flowpipe array (Vitrodynamics, Rockaway, NJ) mounted on a piezoelectric bimorph (Vernitron, Bedford, $\mathrm{OH}$ ). A computer-controlled constant current source drove the bimorph to move solution interfaces over the patch with $10-90 \%$ exchange times of $\sim 200 \mu \mathrm{s}$, as measured by the liquid junction current at the open pipette tip after each experiment. GABA was dissolved in the perfusion solution, which contained the following (in mM): $145 \mathrm{NaCl}, 2.5 \mathrm{KCl}, 2 \mathrm{CaCl}_{2}, 1 \mathrm{MgCl}_{2}, 10 \mathrm{HEPES}$, and 4 glucose, $\mathrm{pH} 7.4,310-325 \mathrm{mOsm}$. Picrotoxin solutions were made by diluting a stock ( 0.1 or $0.3 \mathrm{M}$ in DMSO) to give a final DMSO concentration of $<1 \%$. Preequilibration for $4.9 \mathrm{~s}$ in this concentration of DMSO did not significantly alter receptor kinetics in response to GABA pulses $(25 \mathrm{~ms} ; 10 \mathrm{~mm})$. All salts and drugs were from Sigma-Aldrich. Currents were low-pass filtered at $1-5 \mathrm{kHz}$ with a four-pole Bessel filter and digi- tized at a rate no less than twice the filter frequency. Data were collected using an Axopatch 200B amplifier and Digidata 1320A digitizer, controlled by AxoGraph software (Molecular Devices, Foster City, CA) running on a Macintosh G4 (Apple Computer, Cupertino, CA). Curve fitting was performed using AxoGraph or Matlab 5.2 (Mathworks, Natick, MA). Patch current kinetics typically displayed two to three exponential components, but to allow pooling of fitted parameters from different experiments, we restricted all fits to two components plus a constant when appropriate. We define the weighted time constant as $\tau_{\mathrm{w}}=\Sigma a^{\prime}{ }_{i} \tau_{i}$, where $a_{i}^{\prime}=\left[a_{i} /\left(\sum a_{i}+c\right)\right], a_{i}$ and $\tau_{i}$ are the amplitude and time constant of the $i$ th component, and $c$ is the constant. For deactivation $(c=0), \tau_{\mathrm{w}}$ corresponds to the time of one-half charge transfer, whereas for desensitization $(c \neq 0)$, it is an empirical measure that takes into account both the rate and extent of desensitization (i.e., $\tau_{\mathrm{w}}$ will be large only if underlying components are both slow and large). Unless otherwise noted, values are reported as mean \pm SEM, and significant differences were tested using a two-tailed unpaired Student's $t$ test at a significance level of $p \leq 0.05$.

Open probability analysis. Nonstationary variance analysis (Sigworth, 1980 ) was performed on currents recorded (at voltage $V=-60 \mathrm{mV}$ ) from a series of saturating GABA pulses $(25 \mathrm{~ms} ; 10 \mathrm{~mm})$ interleaved with saturating pulses ( $4.9 \mathrm{~s} ; 0.1-1 \mathrm{~mm}$ ) of the noncompetitive antagonist picrotoxin at an intersweep interval of $10.02 \mathrm{~s}$. The current $(I)$ and its variance $\left(\sigma^{2}\right)$ in the presence of picrotoxin (i.e., $\left.I_{\mathrm{b}}, \sigma_{\mathrm{b}}{ }^{2}\right)$ reflect the true noise baseline at which channel open probability is zero, the "baseline" in the absence of picrotoxin (i.e., $I_{\mathrm{s}}, \sigma_{\mathrm{s}}{ }^{2}$ ) reflects the spontaneous open probability, and the response to saturating GABA (i.e., $I_{\mathrm{e}}, \sigma_{\mathrm{e}}{ }^{2}$ ) reflects the maximally evoked open probability. The ensemble mean current and variance were calculated for each data point under each condition. To accommodate the idea that the baseline current of $\epsilon$-containing receptors includes spontaneous $\mathrm{GABA}_{\mathrm{A}}$ channel openings, the means of the current and variance in the presence of picrotoxin were subtracted from the original values. The subtracted data were then pooled, binned, and plotted as variance versus mean current, yielding a parabola of the form $\sigma^{2}=$ $i I-I^{2} / N$, from which the single channel conductance $(\gamma=i / V)$, the number of channels $(N)$, and the maximum GABA-evoked open probability $\left[P_{\mathrm{o}(\text { evoked })}=I_{\mathrm{e}(\max )} /(i N)\right]$ could be estimated by curve fitting. The spontaneous open probability was then computed as follows: $P_{\mathrm{o}(\text { spont })}=$ $P_{\text {o(evoked) }}\left(I_{\mathrm{s}} / I_{\mathrm{e}}\right)$.

Variance caused by slow drift (i.e., rundown or run-up) was corrected by local linear fitting of the drift, as measured by the change in peak response over a group of traces $(\sim 10)$, calculating the variance caused by this trend, and subtracting it (scaled by the square of normalized current amplitude) from the mean variance within the group before binning and fitting. This method yields accurate estimates of $i$ and $N$ when tested on simulated data with drift.

\section{Results}

The $\epsilon$ subunit confers slow deactivation and slow desensitization

At synapses, $\mathrm{GABA}_{\mathrm{A}}$ receptors are activated by a large $(>1 \mathrm{~mm})$ but brief $(\sim 1 \mathrm{~ms})$ GABA concentration spike (Overstreet et al., 2002). To approximate the likely response of receptors to such a synaptic stimulus, we applied $5 \mathrm{~ms}$ pulses of $10 \mathrm{~mm}$ GABA to outside-out patches containing either $\alpha 2 \beta 1, \alpha 2 \beta 1 \gamma 2$, or $\alpha 2 \beta 1 \epsilon$ receptors (Fig. $1 A$ ). $\alpha 2 \beta 1 \epsilon$ receptors were much slower to deactivate after the GABA pulse than $\alpha 2 \beta 1$ or $\alpha 2 \beta 1 \gamma 2$ receptors. Deactivation was at least biexponential in all cases (Table 1), but fast and slow time constants were twofold to threefold slower, and the relative amplitude of the slow component was larger for $\alpha 2 \beta 1 \epsilon$ receptors. These complex differences can be summarized 
by comparing the weighted average time constant $\left(\tau_{\mathrm{w}}\right)$, which was twofold to fourfold slower for $\alpha 2 \beta 1 \epsilon(109 \pm 12$ $\mathrm{ms} ; n=9)$ than for $\alpha 2 \beta 1(27 \pm 3 \mathrm{~ms}$; $n=10)$ or $\alpha 2 \beta 1 \gamma 2(46 \pm 5 \mathrm{~ms} ; n=6)$. Thus, the $\epsilon$ subunit confers dramatic differences in kinetics, which might manifest as very long-lasting IPSCs if the subunit is present in synaptic receptors.

The time course of deactivation can be influenced by the kinetics of channel gating as well as of GABA unbinding (Jones and Westbrook, 1995). To test whether gating kinetics were altered by the $\epsilon$ subunit, we examined the time course of current during long pulses (3 s) of saturating (10 mM) GABA (Fig. $1 B$, Table 1). Macroscopic desensitization during long GABA pulses was at least biexponential in all cases but was slower for $\alpha 2 \beta 1 \epsilon$ and $\alpha 2 \beta 1 \gamma 2$ than for $\alpha 2 \beta 1$ receptors. The weighted average time constant was approximately twofold slower for $\alpha 2 \beta 1 \epsilon(509 \pm 58 \mathrm{~ms} ; n=3)$ and $\alpha 2 \beta 1 \gamma 2(551 \pm 40$ ms; $n=7)$ than for $\alpha 2 \beta 1(272 \pm 37 \mathrm{~ms} ; n=6)$. Thus, the $\epsilon$ subunit slowed the macroscopic rate of desensitization compared with $\alpha 2 \beta 1$, but not compared with $\alpha 2 \beta 1 \gamma 2$, in contrast to the conclusions of Whiting et al. (1997). Interestingly, the presence of the $\epsilon$ subunit exerted a different profile when examining the extent of desensitization. The extent was greater for $\alpha 2 \beta 1$ (79 \pm $5 \%)$ and $\alpha 2 \beta 1 \epsilon(89 \pm 3 \%)$ than for $\alpha 2 \beta 1 \gamma 2(67 \pm 4 \%)$. Thus, the $\epsilon$ subunit promotes slow but deep desensitization. This behavior is distinct from that of either $\alpha 2 \beta 1$ (in which desensitization is rapid) or $\alpha 2 \beta 1 \gamma 2$ (in which desensitization is slow and shallow).

Finally, after removal of GABA, a small "overshoot" above the baseline current was observed during deactivation of $\epsilon$-containing receptors, but not the others, in 7 of 19 patches (Fig. 1C). Similar overshoots were also present in previous studies of $\epsilon$ subunit-containing receptors (Whiting et al., 1997; Neelands et al., 1999). Because $\epsilon$ causes spontaneous channel opening that contributes to the baseline current (Neelands et al., 1999; Davies et al., 2001, 2002), the overshoot may result from a transient silencing of spontaneous openings, caused by GABA-induced desensitization.

\section{$\epsilon$ confers deep brief-pulse desensitization with slow recovery}

As shown above, the $\epsilon$ subunit confers slow deactivation and desensitization but also appears to enhance the stability of desensitized states. If $\epsilon$ is present at synapses, how might these properties shape transmission? Slow deactivation predicts long-lasting IPSCs that ought to increase the effectiveness of inhibition. Deep desensitization, however, predicts that repetitive activation will cause receptors to accumulate in desensitized states, imparting a frequency-dependent "rundown" in IPSC size and reducing the effectiveness of inhibition (Jones and Westbrook, 1996). To further evaluate the possible synaptic implications of $\epsilon$-dependent kinetics, we approximated repetitive synaptic stimuli with pairs of brief GABA pulses ( $5 \mathrm{~ms} ; 10 \mathrm{~mm}$ ) separated by varying intervals (Fig. 2). All three receptor types produced smaller responses to the second pulse in a pair, demonstrating that they visit desensitized states during deactivation after a brief pulse. The recovery time course was best fit with a single $(\alpha 2 \beta 1)$ or double $(\alpha 2 \beta 1 \gamma 2$ and $\alpha 2 \beta 1 \epsilon$ ) exponential function. However, the time constants
A

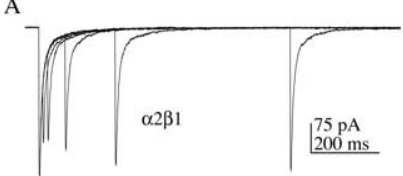

B

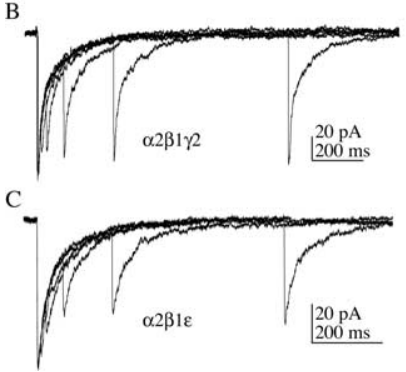

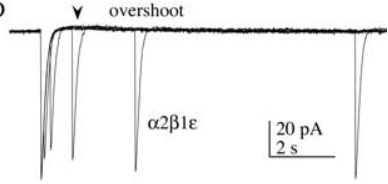

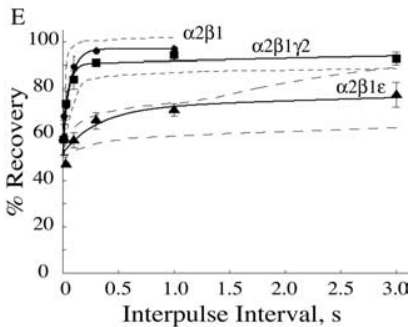

Figure 2. The $\epsilon$ subunit confers slow recovery after brief GABA pulses. $\boldsymbol{A}-\boldsymbol{C}$, Pairs of brief and saturating GABA pulses ( $5 \mathrm{~ms} ; 10 \mathrm{~mm}$ ), separated by a variable interpulse interval, were applied to patches containing $\alpha 2 \beta 1(\boldsymbol{A}), \alpha 2 \beta 1 \gamma 2(\boldsymbol{B})$, or $\alpha 2 \beta 1 \epsilon(\boldsymbol{C})$ receptors. Different interpulse intervals were interleaved to compensate for slow drifts in amplitude, and responses for each interval were averaged and normalized to the peak of the first pulse. The second pulse in each pair was depressed for all receptor types. However, both deactivation and recovery from pairedpulse depression were slower in $\alpha 2 \beta 1 \epsilon$ than in $\alpha 2 \beta 1$ and $\alpha 2 \beta 1 \gamma 2$ receptors, which were indistinguishable from each other. $\boldsymbol{D}$, The same experiment on $\alpha 2 \beta 1 \epsilon$ receptors shown in $\boldsymbol{C}$, over a larger time scale. Note the consistent presence of small outward overshoot currents after even brief pulses. $\boldsymbol{E}$, Recovery versus interpulse interval. Recovery was defined as follows: $\left(P_{2}-\right.$ offset $) /\left(P_{1}\right.$ - offset), where $P_{1}$ and $P_{2}$ are the peak amplitude of the first and second responses, measured from the resting baseline, and offset is the current immediately before the start of the second response. The symbols and error bars are mean \pm SEM, and the solid lines are biexponential fits with an asymptote constrained to reach to $100 \%$ (see Table 1 for fitted parameters). The dashed lines are $95 \%$ confidence limits established by bootstrapping, similar to that described by Jones et al. (2001). The short dashes are the combined outer $95 \%$ limits for $\alpha 2 \beta 1$ and $\alpha 2 \beta 1 \gamma 2$, the inner limits (data not shown) of which overlapped significantly, indicating that their recovery kinetics are statistically indistinguishable. In contrast, the long dashes are the limits for $\alpha 2 \beta 1 \epsilon$ and clearly do not overlap the recovery time course of the other two receptor types.

and fractional contribution of the slow phase of recovery were much larger for $\epsilon$-containing receptors (Table 1 ). The prominence of the slow phase of recovery in $\epsilon$-containing receptors suggests that the recovery time course is dominated by visits to a slow desensitized state that is highly stable or frequently visited. The paired-pulse protocol does not measure the actual micro- 


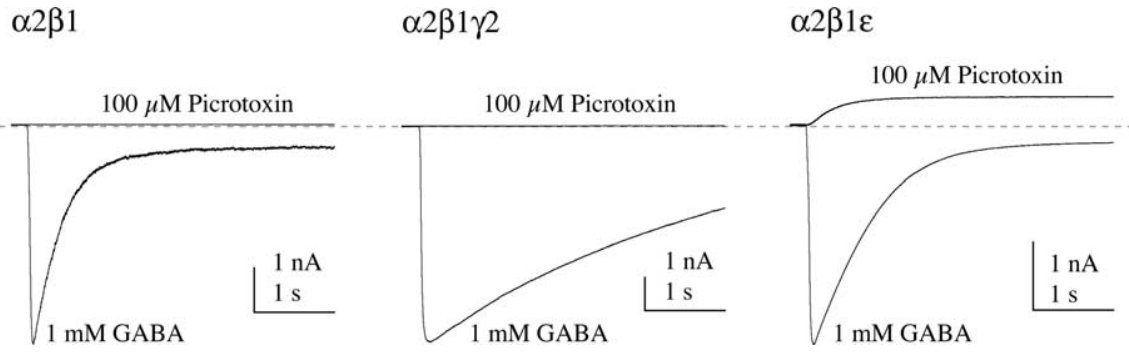

Figure 3. The $\epsilon$ subunit confers picrotoxin-sensitive spontaneous channel opening. GABA and the noncompetitive $G A B A_{A}$ receptor antagonist picrotoxin were alternately applied by pressure to intact HEK293 cells transfected with $\alpha 2 \beta 1, \alpha 2 \beta 1 \gamma 2$, or $\alpha 2 \beta 1 \epsilon$ receptors. Picrotoxin had no effect on the resting current for $\alpha 2 \beta 1$ or $\alpha 2 \beta 1 \gamma 2$ receptors but caused a large outward current for $\alpha 2 \beta 1 \epsilon$ receptors, suggesting that these receptors are open spontaneously.

scopic rate of leaving desensitized states but rather the total time required to return to the unbound state. Therefore, after binding GABA, $\alpha 2 \beta 1 \epsilon$ receptors appear to remain bound for much longer than $\alpha 2 \beta 1$ or $\alpha 2 \beta 1 \gamma 2$ receptors. This could be solely attributable to the gating differences observed here or could also reflect a slowed microscopic GABA unbinding rate. Finally, we also observed overshoots after brief GABA pulses in $\epsilon$ subunitcontaining receptors (Fig. $2 D$ ). Because currents in outside-out patches are small (tens of picoamperes), and overshoot amplitudes are only a few percentage of that, we were not able to rigorously quantify the overshoot kinetics. However, from the example in Figure $2 D$, it appears that the overshoot lasts approximately as long as recovery from brief-pulse desensitization, again suggesting that GABA-induced desensitization transiently silences spontaneously open channels that contribute to the baseline current.

\section{Evoked and spontaneous open probabilities}

The ability of $\epsilon$ subunit-containing receptors to open spontaneously may have important implications for neural excitability. The impact of a channel on excitability depends on (1) the channel reversal potential $\left(E_{\mathrm{Cl}}\right),(2)$ the single-channel conductance $(\gamma),(3)$ the number of channels expressed $(N)$, and (4) the probability of each channel being open $\left(P_{\mathrm{o}}\right)$. For spontaneously opening receptors, the spontaneous and evoked open probabilities $\left(P_{\mathrm{o} \text { (spont })}, P_{\mathrm{o} \text { (evoked) }}\right)$ must also be distinguished from each other. We used nonstationary variance analysis (Sigworth, 1980) (see Materials and Methods) to estimate the spontaneous and maximal evoked open probability of $\epsilon$-containing receptors.

First, to confirm that the baseline current contains a contribution of spontaneously open $\mathrm{GABA}_{\mathrm{A}}$ receptors (Neelands et al., 1999; Davies et al., 2001; Maksay et al., 2003), we compared responses to pressure applications of GABA (1 mM) and the noncompetitive antagonist picrotoxin $(100 \mu \mathrm{M})$ to intact HEK293 cells transfected with $\alpha 2 \beta 1, \alpha 2 \beta 1 \gamma 2$, or $\alpha 2 \beta 1 \epsilon$ subunit combinations (Fig. 3). All receptor types responded to GABA with large inward currents. However, picrotoxin had no effect on the inward baseline current of cells expressing $\alpha 2 \beta 1$ or $\alpha 2 \beta 1 \gamma 2$ receptors (four of four cells each), whereas it reduced the inward baseline current in cells expressing $\alpha 2 \beta 1 \epsilon$ receptors (four of four cells). The magnitude of the reduction in baseline current was $8.8 \pm 2.4 \%$ of the magnitude of inward current evoked by $1 \mathrm{~mm}$ GABA. This estimate is lower than that reported previously $(20 \pm$ $3 \%)$, using slower applications of GABA $(100 \mu \mathrm{M})$ and picrotoxin (1 mM) to oocytes (Mortensen et al., 2003). It is important to note that slow solution exchange biases peak current estimates toward lower values (Wagner et al., 2004), thus inflating the ratio of spontaneous current to peak GABA-evoked current.
To accurately quantify the open probabilities, we used repeated alternating rapid applications of picrotoxin (0.1-1 $\mathrm{mm})$ and GABA (10 $\mathrm{mm})$ to outside-out patches expressing $\alpha 2 \beta 1 \epsilon$ receptors. Each sweep contained a stretch of "control" data reflecting the spontaneous current $\left(I_{\mathrm{s}}\right)$ (Fig. 4A), followed by application of picrotoxin on alternate sweeps to block spontaneously open receptors and reveal the true baseline current $\left(I_{\mathrm{b}}\right)$ (Fig. $4 B$ ), followed by a $25 \mathrm{~ms}$ pulse of $10 \mathrm{~mm}$ GABA to evaluate the maximal evoked current $\left(I_{\mathrm{e}}\right)$ (Fig. $4 C$ ). By repeating this pattern many times on each patch, we generated ensembles of responses from which the mean currents $\left(I_{\mathrm{s}}, I_{\mathrm{b}}\right.$, and $\left.I_{\mathrm{e}}\right)$ and their variances $\left(\sigma_{\mathrm{s}}^{2}, \sigma_{\mathrm{b}}^{2}, \sigma_{\mathrm{e}}^{2}\right)$ were computed at each time point. Plots of mean-versus-variance (Fig. $4 D, E$ ) were fit with a parabolic equation, yielding estimates of the single-channel conductance, the number of channels in each patch, and the maximal GABA-evoked and spontaneous open probabilities (see Materials and Methods). The single-channel conductance estimated by variance analysis reflects an average over all subconductance levels, weighted by their probability, and was $28 \pm 14 \mathrm{pS}$ for $\alpha 2 \beta 1 \epsilon$ receptors $(n=5)$, within the range of $13-36 \mathrm{pS}$ measured directly from single-channel records (Neelands et al., 1999; Davies et al., 2001). The number of channels per patch varied widely (mean \pm SEM, $82 \pm 43$; range, $8-230$ ), as did the evoked and spontaneous current amplitudes $\left(I_{\mathrm{e}}=34 \pm 11 \mathrm{pA} ; I_{\mathrm{s}}=2 \pm 1 \mathrm{pA}\right)$, but the maximal evoked open probability was relatively reproducible $\left(P_{\mathrm{o} \text { (evoked) }}=0.62 \pm 0.09\right)$. The spontaneous open probability computed from these values was $0.04 \pm 0.02$. Therefore, $\alpha 2 \beta 1 \epsilon$ receptors spend $\sim 4 \%$ of the time open at steady state in the absence of GABA.

\section{Discussion}

\section{Kinetic changes conferred by the $\epsilon$ subunit}

$\alpha 2 \beta 1 \epsilon$ receptors are kinetically distinct from $\alpha 2 \beta 1$ and $\alpha 2 \beta 1 \gamma 2$ receptors. The $\epsilon$ subunit slows deactivation and brief-pulse recovery in general, slows desensitization compared with $\alpha 2 \beta 1$, and enhances the extent of desensitization compared with $\alpha 2 \beta 1 \gamma 2$. Furthermore, only $\alpha 2 \beta 1 \epsilon$ receptors display an overshoot representing the transient silencing of channels by desensitization, which are spontaneously open $\sim 4 \%$ of the time in the absence of GABA.

Macroscopic desensitization could be altered by changing microscopic rates of channel opening, closing, desensitization, or resensitization. Neelands et al. (1999) showed that the intraburst single-channel parameters of $\alpha 1 \beta 3 \epsilon$ receptors are intermediate between those of $\alpha 1 \beta 3$ and $\alpha 1 \beta 3 \gamma 2 \mathrm{~L}$. Closing rates are twofold to sixfold slower and burst durations are onefold to threefold longer for $\alpha 1 \beta 3 \epsilon$ or $\alpha 1 \beta 3 \gamma 2 \mathrm{~L}$ than for $\alpha 1 \beta 3$. Although caution is required when comparing studies using different $\alpha$ and $\beta$ isoforms, high stabilities of open or burst states in $\alpha 2 \beta 1 \gamma 2$ or $\alpha 2 \beta 1 \epsilon$ receptors could contribute to the slow deactivation and desensitization rates we observe here, compared with $\alpha 2 \beta 1$ receptors. However, unlike the intraburst kinetics, the macroscopic kinetics of $\alpha 2 \beta 1 \epsilon$ receptors are clearly not intermediate between those of $\alpha 2 \beta 1$ and $\alpha 2 \beta 1 \gamma 2$. For example, $\alpha 2 \beta 1 \epsilon$ receptors have slower deactivation and brief pulse recovery than either of the others. Thus, differences solely in intraburst kinetics (i.e., opening/closing) are unlikely to explain the distinct kinetics conferred by the $\epsilon$ subunit, 


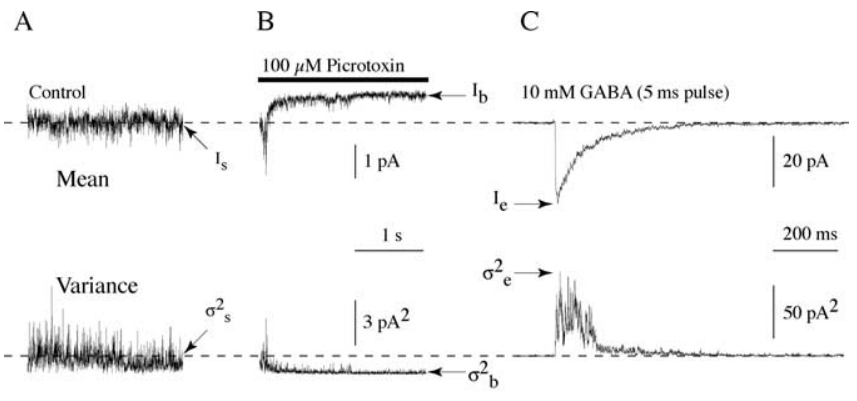

D
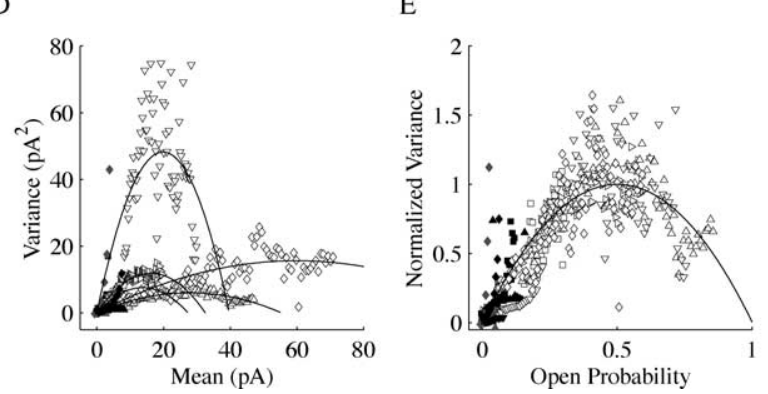

Figure 4. Spontaneous open probability of $\alpha 2 \beta 1 \epsilon$ receptors quantified by nonstationary variance analysis. $\boldsymbol{A}$, The mean ( $I_{s} ;$ top) and variance $\left(\sigma^{2}{ }_{s} ;\right.$ bottom) of the resting (spontaneous) current in outside-out patches in the absence of GABA or picrotoxin (see Materials and Methods and Results). $\boldsymbol{B}$, Picrotoxin reduces the mean current and variance to reveal the true baseline $\left(I_{\mathrm{b}}\right.$, top; $\sigma_{b}^{2}$, bottom). Note the brief transient increase in both mean current and variance after application of picrotoxin. Such a transient was observed in several experiments, but its mechanistic significance remains unknown. $\boldsymbol{C}$, Saturating GABA pulses reveal the maximal evoked mean current $\left(I_{\mathrm{e}} ;\right.$ top) and variance $\left(\sigma_{\mathrm{e}}^{2} ;\right.$ bottom). $\boldsymbol{D}$, Variance versus mean plots for five outside-out patch experiments. Each symbol type and solid line are data and the corresponding parabolic fit from a separate patch, respectively. Each data point is the result of binning (averaging) individual sample points so that 100 bins spanned the full amplitude range of the GABAevoked current. The open symbols are from the GABA-evoked responses $(\boldsymbol{C})$, gray symbols are in the presence of picrotoxin $(\boldsymbol{B})$, and black symbols are from the resting current $(\boldsymbol{A})$. $\boldsymbol{E}$, The same data from $\boldsymbol{D}$, pooled and normalized on the horizontal axis to the open probability estimated from the separate fit for each experiment and normalized on the vertical axis to the fitted maximal variance. Visually, the maximal evoked open probability $\left(P_{\text {o(evoked) }}\right)$ corresponds to the horizontal axis location of the rightmost open symbol (average, $\sim 0.6$ ), whereas the mean spontaneous open probability $\left(P_{\text {o(spont })}\right)$ corresponds to the location of the mean of the black symbols (average, $\sim 0.04$ ).

and interburst processes (i.e., binding/unbinding or desensitization/resensitization) must also be altered.

The simplest explanation for the slow, but large, macroscopic desensitization in $\alpha 2 \beta 1 \epsilon$ is that the $\epsilon$ subunit slows resensitization. The equilibration time constant $\left(\tau_{\text {eq }}\right)$ between two collections of states [in this case, available $(A)$ and desensitized $(D)$ states] is the inverse sum of the forward [desensitization $(d)$ ] and backward [resensitization $(r)]$ rates connecting them $\left[\tau_{\text {eq }}=1 /(d+r)\right]$, whereas the fractional extent $(E)$ of equilibration is determined by a ratio of rates $[E=D /(A+D)=d /(d+r)]$. Reducing either rate slows the time constant, but only reducing resensitization also enhances accumulation in desensitized states. Slowing resensitization would also contribute to the slowed brief-pulse recovery observed in $\alpha 2 \beta 1 \epsilon$ receptors. Our empirical measure of the desensitization time constant $\left(\tau_{\mathrm{w}}\right)$ is the equilibration time constant scaled by the extent $\left[\tau_{\mathrm{w}}=E \tau_{\mathrm{eq}}\right]$, from which a rough estimate of the mean desensitization $\left(d=E^{2} / \tau_{\mathrm{w}}\right)$ and resensitization $\left(r=E / \tau_{\mathrm{w}}-d\right)$ rates can be obtained by plugging in the weighted desensitization time constants $(\alpha 2 \beta 1,0.272 \mathrm{~s} ; \alpha 2 \beta 1 \gamma 2,0.551 \mathrm{~s} ; \alpha 2 \beta 1 \epsilon, 0.509 \mathrm{~s})$ and fractional extents of desensitization ( $\alpha 2 \beta 1,0.79 ; \alpha 2 \beta 1 \gamma 2,0.67 ; \alpha 2 \beta 1 \epsilon, 0.89)$. This yields $d$, the mean rate of leaving the collection of available states $\left(\alpha 2 \beta 1,2.3 \mathrm{~s}^{-1} ; \alpha 2 \beta 1 \gamma 2,0.8 \mathrm{~s}^{-1} ; \alpha 2 \beta 1 \epsilon, 1.6 \mathrm{~s}^{-1}\right)$, from which $r$ can be computed $\left(\alpha 2 \beta 1,0.60 \mathrm{~s}^{-1} ; \alpha 2 \beta 1 \gamma 2,0.42 \mathrm{~s}^{-1} ; \alpha 2 \beta 1 \epsilon, 0.15 \mathrm{~s}^{-1}\right)$. Note that $r$ is threefold to fourfold slower in $\epsilon$-containing receptors, as predicted. Thus, the $\epsilon$ subunit slows resensitization, which both slows and enhances the depth of macroscopic desensitization, as well as slowing brief-pulse recovery.

It is also likely that the GABA unbinding rate has been reduced by the $\epsilon$ subunit. $\epsilon$ subunit-containing receptors desensitize slowly but reach the same level of desensitization as the other receptors early during deactivation (Fig. 2E, Table 1 ). In order for this to occur, the time spent in desensitizable states must increase in proportion to the slowing of $d$ (approximately twofold), consistent with a slowed GABA unbinding rate.

In summary, the $\epsilon$ subunit confers a specific profile of kinetics, including slow microscopic closing, resensitization, and possibly GABA unbinding rates, and increases the ability of the channel to open spontaneously (discussed below). This profile predicts that $\epsilon$ subunit-containing receptors should spend considerably more time in GABA-bound states than should $\alpha \beta$ or $\alpha \beta \gamma$ receptors. It is therefore perplexing that whole-cell measurements have not revealed a high apparent affinity for $\alpha \beta \epsilon$ relative to $\alpha \beta$ receptors (Davies et al., 1997; Whiting et al., 1997; Neelands et al., 1999). A possible explanation for this discrepancy is that the GABA binding rate has also been slowed by the $\epsilon$ subunit.

\section{Structural changes conferred by the $\epsilon$ subunit}

The functional hallmarks of the $\epsilon$ subunit may all share the same underlying structural causes. Indeed, a single structural element of the receptor, the pore-lining second transmembrane (TM2) $\alpha$-helix, is implicated in all of these functions (Mihic et al., 1997; Chang and Weiss, 1999; Scheller and Forman, 2002). Replacement of the TM2 9' leucine by serine in the $\mathrm{GABA}_{\mathrm{A}}$ receptor $\alpha, \beta$, or $\gamma 2$ subunits causes spontaneous gating (Chang and Weiss, 1999), and replacement of either the $\gamma 2$ or $\alpha 1$ subunit $9^{\prime}$ leucines by serine (Bianchi and Macdonald, 2001) or threonine (Scheller and Forman, 2002) slows desensitization and deactivation.

All GABA $A_{A}$ receptor subunits have a 9' leucine; thus, this residue is not responsible for the unique properties conferred by the $\epsilon$ subunit. In contrast, the TM2 15' residue is less well conserved and influences spontaneous gating, deactivation kinetics, and anesthetic sensitivity (Scheller and Forman, 2002). The $\alpha, \gamma$, and $\beta 1$ subunits all have $15^{\prime}$ serine residues, whereas the $\beta 2$ and $\beta 3$ subunits have $15^{\prime}$ asparagines. Replacement of the $\beta 1$ subunit $15^{\prime}$ serine by asparagine confers loreclezole and etomidate sensitivity to heteromeric receptors and prevents the spontaneous gating exhibited by wild-type homomeric $\beta 1$ receptors (Wingrove et al., 1994; Belelli et al., 1997; Miko et al., 2004). The $\epsilon$ subunit has a 15' glycine residue. Introduction of a $15^{\prime}$ glycine into homomeric $\beta 1$ receptors supported GABA-independent current, suggesting that a glycine at this position in the $\epsilon$ subunit could account for spontaneous gating. Replacement of the $\alpha 1$ subunit $15^{\prime}$ serine by isoleucine also induced spontaneous gating but had no effect on the rate of desensitization, although deactivation and recovery from desensitization were slowed (Scheller and Forman, 2002). In contrast, the $\epsilon$ subunit slows all three of these functions. Therefore, if the $15^{\prime}$ glycine is involved, it may not account for all of the properties conferred by the $\epsilon$ subunit. Mutations at sites outside of the TM2 domain (the N-terminal domain and TM3) also induce spontaneous gating or altered anesthetic modulation (Mihic et al., 1997; Ueno et al., 1999; Newell et al., 2004), and although the residues implicated in anesthetic resistance and spontaneous gating at these loci are not present in the $\epsilon$ subunit, the participation of non-TM2 regions cannot be ruled out. 
It is interesting that the functional effects of the $\epsilon$ subunit are similar to some of the most consistent effects of general anesthetics on $\epsilon$-lacking receptors, namely, to slow deactivation and induce spontaneous openings. In addition, inclusion of the $\epsilon$ subunit occludes anesthetic potentiation. We speculate that the presence of the $\epsilon$ subunit places the receptor into a state structurally similar to one induced by general anesthetics and, therefore, one on which anesthetics can exert little additional influence.

\section{Physiological implications}

Evidence for the participation of the $\epsilon$ subunit in neuronal inhibition is not yet definitive, although experiments suggest that it is expressed at synapses in the hypothalamus and NTS (Kasparov et al., 2001; Sergeeva et al., 2005). Furthermore, the native subunit partners in $\epsilon$ subunit-containing receptors remain unknown. However, the $\epsilon$ subunit appears to play a dominant functional role when expressed with different $\alpha, \beta$, and even $\gamma$ subunits (Davies et al., 1997, 2001; Whiting et al., 1997; Neelands et al., 1999). Therefore, our kinetic observations make general testable predictions about the likely physiological impact of the $\epsilon$ subunit. First, slow deactivation predicts long-lasting IPSCs. Indeed, IPSCs in $\epsilon$ subunit-containing hypothalamic neurons are significantly longer than those in neurons that lack the $\epsilon$ subunit (Sergeeva et al., 2005). Second, slow recovery from desensitization predicts that IPSCs should run down during repetitive activation, imparting a strong frequency dependence to synaptic inhibition (Jones and Westbrook, 1995, 1996; Bianchi et al., 2002). Therefore, these synapses would be most effective when activated at low frequencies.

Whether synaptic or extrasynaptic, the spontaneous opening of $\epsilon$ subunit-containing receptors predicts a tonic inhibitory current. The spontaneous open probability of $\sim 0.04$, coupled with the single-channel conductance of $\sim 30 \mathrm{pS}$, yields a conductance of $1.2 \mathrm{nS}$ per 1000 channels. Therefore, if expressed at levels comparable with other neuronal $\mathrm{GABA}_{\mathrm{A}}$ receptors, $\epsilon$ subunitcontaining receptors are likely to account for a significant fraction of the resting input conductance and thus exert a dramatic influence on neuronal excitability. However, because of the deep desensitization induced by exposure to GABA, tonic inhibition mediated by $\epsilon$ subunit-containing receptors would behave differently from that mediated by $\delta$ subunit-containing receptors. The latter have little desensitization; thus, prolonged elevations in ambient GABA concentrations would increase tonic inhibition through $\delta$ subunit-containing receptors. In contrast, $\epsilon$ subunitcontaining receptors may respond to prolonged increases in ambient GABA by desensitizing and reducing their contribution to inhibitory tone. If these receptors are exposed to large pulses of GABA, such as would occur at synapses or perhaps by spillover of GABA onto extrasynaptic receptors, the overshoot phenomenon predicts a large reduction in spontaneously open channels, potentially reducing the resting neuronal input conductance significantly. In this scenario, large IPSCs would be followed by a transient period of hyperexcitability. An intriguing possibility is that $\epsilon$ subunit-mediated tonic inhibition, by being transiently downregulated by intermittent phasic inhibition, could contribute to neuronal oscillations at low frequencies determined by the characteristic kinetics of this subunit.

\section{References}

Baulac S, Huberfeld G, Gourfinkel-An I, Mitropoulou G, Beranger A, Prud'homme JF, Baulac M, Brice A, Bruzzone R, LeGuern E (2001) First genetic evidence of $\mathrm{GABA}_{\mathrm{A}}$ receptor dysfunction in epilepsy: a mutation in the $\gamma 2$-subunit gene. Nat Genet 28:46-48.
Belelli D, Lambert JJ, Peters JA, Wafford K, Whiting PJ (1997) The interaction of the general anesthetic etomidate with the gamma-aminobutyric acid type A receptor is influenced by a single amino acid. Proc Natl Acad Sci USA 94:11031-11036.

Belelli D, Casula A, Ling A, Lambert JJ (2002) The influence of subunit composition on the interaction of neurosteroids with $\mathrm{GABA}_{\mathrm{A}}$ receptors. Neuropharmacology 43:651-661.

Bianchi MT, Macdonald RL (2001) Mutation of the 9 ' leucine in the $\mathrm{GABA}_{\mathrm{A}}$ receptor $\gamma 2 \mathrm{~L}$ subunit produces an apparent decrease in desensitization by stabilizing open states without altering desensitized states. Neuropharmacology 41:737-744.

Bianchi MT, Macdonald RL (2002) Slow phases of GABA receptor desensitization: structural determinants and possible relevance for synaptic function. J Physiol (Lond) 544:3-18.

Bonnert TP, McKernan RM, Farrar S, le Bourdelles B, Heavens RP, Smith DW, Hewson L, Rigby MR, Sirinathsinghji DJ, Brown N, Wafford KA, Whiting PJ (1999) $\theta$, a novel gamma-aminobutyric acid type A receptor subunit. Proc Natl Acad Sci USA 96:9891-9896.

Bowser DN, Wagner DA, Czajkowski C, Cromer BA, Parker MW, Wallace RH, Harkin LA, Mulley JC, Marini C, Berkovic SF, Williams DA, Jones MV, Petrou S (2002) Altered kinetics and benzodiazepine sensitivity of a $\mathrm{GABA}_{\mathrm{A}}$ receptor subunit mutation $\left[\gamma_{2}(\mathrm{R} 43 \mathrm{Q})\right]$ found in human epilepsy. Proc Natl Acad Sci USA 99:15170-15175.

Chang Y, Weiss DS (1999) Allosteric activation mechanism of the $\alpha 1 \beta 2 \gamma 2$ gamma-aminobutyric acid type A receptor revealed by mutation of the conserved M2 leucine. Biophys J 77:2542-2551.

Davies PA, Hanna MC, Hales TG, Kirkness EF (1997) Insensitivity to anaesthetic agents conferred by a class of $\mathrm{GABA}_{\mathrm{A}}$ receptor subunit. Nature 385:820-823.

Davies PA, Kirkness EF, Hales TG (2001) Evidence for the formation of functionally distinct $\alpha \beta \gamma \epsilon \mathrm{GABA}_{\mathrm{A}}$ receptors. J Physiol (Lond) 537:101-113.

Davies PA, McCartney MR, Wang W, Hales TG, Kirkness EF (2002) Alternative transcripts of the $\mathrm{GABA}_{\mathrm{A}}$ receptor epsilon subunit in human and rat. Neuropharmacology 43:467-475.

Farrant M, Nusser Z (2005) Variations on an inhibitory theme: phasic and tonic activation of $\mathrm{GABA}_{\mathrm{A}}$ receptors. Nat Rev Neurosci 6:215-229.

Feng HJ, Macdonald RL (2004) Multiple actions of propofol on $\alpha \beta \gamma$ and $\alpha \beta \delta \mathrm{GABA}_{\mathrm{A}}$ receptors. Mol Pharmacol 66:1517-1524.

Feng HJ, Bianchi MT, Macdonald RL (2004) Pentobarbital differentially modulates $\alpha 1 \beta 3 \delta$ and $\alpha 1 \beta 3 \gamma 2 \mathrm{~L} \mathrm{GABA}_{\mathrm{A}}$ receptor currents. Mol Pharmacol 66:988-1003.

Fisher JL, Macdonald RL (1997) Single channel properties of recombinant $\mathrm{GABA}_{\mathrm{A}}$ receptors containing $\gamma 2$ or $\delta$ subtypes expressed with $\alpha 1$ and $\beta 3$ subtypes in mouse L929 cells. J Physiol (Lond) 505:283-297.

Haas KF, Macdonald RL (1999) GABA $_{\mathrm{A}}$ receptor subunit $\gamma 2$ and $\delta$ subtypes confer unique kinetic properties on recombinant $\mathrm{GABA}_{\mathrm{A}}$ receptor currents in mouse fibroblasts. J Physiol (Lond) 514:27-45.

Harkin LA, Bowser DN, Dibbens LM, Singh R, Phillips F, Wallace RH, Richards MC, Williams DA, Mulley JC, Berkovic SF, Scheffer IE, Petrou S (2002) Truncation of the $\mathrm{GABA}_{\mathrm{A}}$-receptor $\gamma 2$ subunit in a family with generalized epilepsy with febrile seizures plus. Am J Hum Genet 70:530-536.

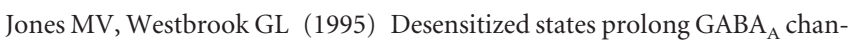
nel responses to brief agonist pulses. Neuron 15:181-191.

Jones MV, Westbrook GL (1996) The impact of receptor desensitization on fast synaptic transmission. Trends Neurosci 19:96-101.

Jones MV, Harrison NL, Pritchett DB, Hales TG (1995) Modulation of the $\mathrm{GABA}_{\mathrm{A}}$ receptor by propofol is independent of the $\gamma$ subunit. J Pharmacol Exp Ther 274:962-968.

Jones MV, Jonas P, Sahara Y, Westbrook GL (2001) Microscopic kinetics and energetics distinguish $\mathrm{GABA}_{\mathrm{A}}$ receptor agonists from antagonists. Biophys J 81:2660-2670.

Kasparov S, Davies KA, Patel UA, Boscan P, Garret M, Paton JF (2001) $\mathrm{GABA}_{\mathrm{A}}$ receptor $\epsilon$ subunit may confer benzodiazepine insensitivity to the caudal aspect of the nucleus tractus solitarii of the rat. J Physiol (Lond) 536:785-796.

Luscher B, Keller CA (2004) Regulation of $\mathrm{GABA}_{\mathrm{A}}$ receptor trafficking, channel activity, and functional plasticity of inhibitory synapses. Pharmacol Ther 102:195-221.

Maksay G, Thompson SA, Wafford KA (2003) The pharmacology of spon- 
taneously open $\alpha 1 \beta 3 \epsilon \mathrm{GABA}_{\mathrm{A}}$ receptor-ionophores. Neuropharmacology 44:994-1002.

Mehta AK, Ticku MK (1999) An update on $\mathrm{GABA}_{\mathrm{A}}$ receptors. Brain Res Brain Res Rev 29:196-217.

Mihic SJ, Ye Q, Wick MJ, Koltchine VV, Krasowski MD, Finn SE, Mascia MP, Valenzuela CF, Hanson KK, Greenblatt EP, Harris RA, Harrison NL (1997) Sites of alcohol and volatile anaesthetic action on $\mathrm{GABA}_{\mathrm{A}}$ and glycine receptors. Nature 389:385-389.

Miko A, Werby E, Sun H, Healey J, Zhang L (2004) A TM2 residue in the $\beta 1$ subunit determines spontaneous opening of homomeric and heteromeric gamma-aminobutyric acid-gated ion channels. J Biol Chem 279: 22833-22840.

Mortensen M, Wafford KA, Wingrove P, Ebert B (2003) Pharmacology of $\mathrm{GABA}_{\mathrm{A}}$ receptors exhibiting different levels of spontaneous activity. Eur J Pharmacol 476:17-24.

Neelands TR, Fisher JL, Bianchi M, Macdonald RL (1999) Spontaneous and gamma-aminobutyric acid $(\mathrm{GABA})$-activated $\mathrm{GABA}_{\mathrm{A}}$ receptor channels formed by $\epsilon$ subunit-containing isoforms. Mol Pharmacol 55:168-178.

Newell JG, McDevitt RA, Czajkowski C (2004) Mutation of glutamate 155 of the $\mathrm{GABA}_{\mathrm{A}}$ receptor $\beta 2$ subunit produces a spontaneously open channel: a trigger for channel activation. J Neurosci 24:11226-11235.

Nusser Z, Sieghart W, Somogyi P (1998) Segregation of different GABA receptors to synaptic and extrasynaptic membranes of cerebellar granule cells. J Neurosci 18:1693-1703.

Overstreet LS, Westbrook GL, Jones MV (2002) Measuring and modeling the spatiotemporal profile of GABA at the synapse. In: Transmembrane transporters (Quick M, ed), pp 259-275. New York: Wiley.

Scheller M, Forman SA (2002) Coupled and uncoupled gating and desensitization effects by pore domain mutations in $\mathrm{GABA}_{\mathrm{A}}$ receptors. J Neurosci 22:8411-8421.

Sergeeva OA, Andreeva N, Garret M, Scherer A, Haas HL (2005) Pharmacological properties of $\mathrm{GABA}_{\mathrm{A}}$ receptors in rat hypothalamic neurons expressing the $\epsilon$ subunit. J Neurosci 25:88-95.

Sigworth FJ (1980) The variance of sodium current fluctuations at the node of Ranvier. J Physiol (Lond) 307:97-129.

Sinkkonen ST, Hanna MC, Kirkness EF, Korpi ER (2000) GABA A receptor $\epsilon$ and $\theta$ subunits display unusual structural variation between species and are enriched in the rat locus ceruleus. J Neurosci 20:3588-3595.

Stell BM, Brickley SG, Tang CY, Farrant M, Mody I (2003) Neuroactive steroids reduce neuronal excitability by selectively enhancing tonic inhibition mediated by $\delta$ subunit-containing $\mathrm{GABA}_{\mathrm{A}}$ receptors. Proc Natl Acad Sci USA 100:14439-14444.

Thompson SA, Bonnert TP, Cagetti E, Whiting PJ, Wafford KA (2002) Overexpression of the $\mathrm{GABA}_{\mathrm{A}}$ receptor $\epsilon$ subunit results in insensitivity to anaesthetics. Neuropharmacology 43:662-668.

Ueno S, Wick MJ, Ye Q, Harrison NL, Harris RA (1999) Subunit mutations affect ethanol actions on $\mathrm{GABA}_{\mathrm{A}}$ receptors expressed in Xenopus oocytes. Br J Pharmacol 127:377-382.

Wagner DA, Czajkowski C, Jones MV (2004) An arginine involved in GABA binding and unbinding but not gating of the $\mathrm{GABA}_{\mathrm{A}}$ receptor. J Neurosci 24:2733-2741.

Wallace RH, Marini C, Petrou S, Harkin LA, Bowser DN, Panchal RG, Williams DA, Sutherland GR, Mulley JC, Scheffer IE, Berkovic SF (2001) Mutant $\mathrm{GABA}_{\mathrm{A}}$ receptor $\gamma 2$-subunit in childhood absence epilepsy and febrile seizures. Nat Genet 28:49-52.

Whiting PJ, McAllister G, Vassilatis D, Bonnert TP, Heavens RP, Smith DW, Hewson L, O’Donnell R, Rigby MR, Sirinathsinghji DJ, Marshall G, Thompson SA, Wafford KA, Vasilatis D (1997) Neuronally restricted RNA splicing regulates the expression of a novel $\mathrm{GABA}_{\mathrm{A}}$ receptor subunit conferring atypical functional properties. J Neurosci 17:5027-5037.

Whiting PJ, Bonnert TP, McKernan RM, Farrar S, Le Bourdelles B, Heavens RP, Smith DW, Hewson L, Rigby MR, Sirinathsinghii DJ, Thompson SA, Wafford KA (1999) Molecular and functional diversity of the expanding $\mathrm{GABA}_{\mathrm{A}}$ receptor gene family. Ann NY Acad Sci 868:645-653.

Wingrove PB, Wafford KA, Bain C, Whiting PJ (1994) The modulatory action of loreclezole at the gamma-aminobutyric acid type A receptor is determined by a single amino acid in the $\beta 2$ and $\beta 3$ subunit. Proc Natl Acad Sci USA 91:4569-4573.

Wohlfarth KM, Bianchi MT, Macdonald RL (2002) Enhanced neurosteroid potentiation of ternary $\mathrm{GABA}_{\mathrm{A}}$ receptors containing the $\delta$ subunit. J Neurosci 22:1541-1549. 